\title{
APRENDIZAGEM DA DOCÊNCIA EM UMA COMUNIDADE DE PRÁTICA: O PROFESSOR DOS ANOS INICIAIS E O ENSINO DE MATEMÁTICA
}

\author{
Teachers learning in a community of practice: the teacher of the early years of \\ elementary school and mathematics teaching
}

\author{
Aprendizaje de la docencia en una comunidad de prática: el profesor de los años \\ iniciales y la enseñanza de la matemática
}

\author{
Sara Miranda de Lacerda* \\ Ana Lúcia Manrique*
}

\begin{abstract}
Resumo
Este artigo apresenta dados de uma pesquisa de doutorado em andamento vinculada a um projeto em rede aprovado no Programa Observatório da Educação e se insere no contexto da aprendizagem para a docência nos anos iniciais de ensino fundamental para o ensino de Matemática. Tem a intenção de descrever e analisar alguns resultados de duas situações que foram planejadas por professores que ensinam Matemática nos anos iniciais e com estudantes de Pedagogia que participam de uma Comunidade de Prática (WENGER, 2006). Essas situações foram elaboradas pelos participantes, propostas nas salas de aula de dois desses professores, filmadas e, posteriormente, expostas para reflexão e análise pelos integrantes do grupo, em duas seções. Neste caso, houve a intenção de observar a aprendizagem da docência pela reflexão da própria prática em confronto com os pares, com inspiração no processo de autoconfrontação simples e cruzada, proposta por Yves Clot (2007). Os participantes da Comunidade de Prática compartilharam experiências e estudos e isso enriqueceu as discussões e as percepções acerca de sua prática pedagógica. Os resultados mostram que esse movimento promove aprendizagem da docência.
\end{abstract}

PAVALVRA-CHAVE: Ensino de Matemática. Aprendizagem da docência. Comunidade de prática

\begin{abstract}
This paper shows some of the results of a research in progress, which is part of a project approved in the Programa Observatório da Educação and it is inserted in the context of teachers training to teach Mathematics in the early years of elementary school. The intention is to describe and analyze some of the results of two situations that were planned by teachers who teach Mathematics in the early years of elementary school and by students of Pedagogy who participate in a Community of Practice, as suggested by Wenger (2006). These situations have been prepared by the participants, proposed by them in these teachers' classrooms, filmed and subsequently exposed to reflection and analysis by group members in two sections. In this case, the intention was to observe teachers learning by the reflection on the own practice in confrontation with peers, with inspiration in simple and cruised confrontation proposed by Yves Clot (2007). The participants of the Community of Practice share experiences and studies and this process enriches the discussions and perceptions about their practice. The results show that this movement promotes teacher learning.
\end{abstract}

KEYWORDS: Mathematics education. Teachers training. Community of practice

\section{Resumen}

Este artículo presenta los datos de un doctorado en marcha conectado a un proyecto de investigación en red aprobado en el Programa Observatório da Educação y participa en el contexto del aprendizaje de

\footnotetext{
* Doutoranda em Educação Matemática pela PUC/SP; Professora do curso de Pedagogia na faculdade Sumaré. E-mail: saraml@uol.com.br

* Doutora em Educação pelo Programa de Psicologia da Educação da PUC/SP, professora do Programa de Estudos Pós-Graduados em Educação Matemática da PUC/SP, São Paulo, SP, Brasil. E-mail: analuciamanrique@gmail.com
} 
la docencia de la Matemática para los años iniciales de la enseñanza fundamental. Él tiene la intención de describir y analizar algunos resultados de dos situaciones que fueron planeadas por profesores que enseñan Matemática en nos años iniciales y con estudiantes de Pedagogía que participan de una Comunidad de Práctica (WENGER, 2006). Esas situaciones fueron planeadas por los participantes, propuestas en las aulas de dos de eses profesores, filmadas y, después, expuestas para la reflexión y el análisis por los miembros s del grupo, en dos secciones. En este caso, había la intención de observar el aprendizaje de la docencia a partir de la reflexión sobre la propia práctica en confrontación con los pares, con inspiración en el proceso de autoconfrontación simples y cruzado, propuesto por Yves Clot (2007). Los participantes de la Comunidad de Práctica compartieron las experiencias y los estudios y eso enriqueció las discusiones y las percepciones con respecto a su práctica pedagógica. Los resultados muestran que ese movimiento promueve aprendizaje de la docencia.

PALABRAS CLAVES: Enseñanza de la matemática. Aprendizaje de la docencia. Comunidad de práctica

\section{INTRODUÇÃO}

Este artigo apresenta um recorte de uma pesquisa de doutorado1 em andamento cujos dados foram coletados em um grupo de professores e estudantes integrante de um projeto em rede vinculado ao Programa Observatório da Educação, aprovado no Edital 049/2012/CAPES/INEP.

O projeto "Rede Colaborativa de Práticas na Formação de Professores que ensinam Matemática: múltiplos olhares, diálogos e contextos" propõe a criação de uma rede colaborativa entre três programas de Pós-Graduação (UFSCar, PUC/SP e UFABC), com o objetivo de colocar em evidência o potencial da rede de colaboração no processo de constituição profissional do professor que ensina Matemática e promover a aproximação entre universidade e escola pública, em um movimento recíproco de transformação (GAMA; PASSOS e CARDOSO, 2012).

O núcleo da PUC-SP, composto por participantes de três Programas de Pós-Graduação: de Educação Matemática, de Educação: Psicologia da Educação e de Formação de Formadores, organizou um grupo de estudos formado por estudantes de doutorado, estudantes de mestrado acadêmico e mestrado profissional, estudantes de graduação em Pedagogia e Licenciatura em Matemática e professores em efetivo exercício nos anos iniciais e anos finais do ensino fundamental da rede pública de Educação Básica da cidade de São Paulo e arredores como uma das ações para colaborar no estudo das questões propostas no projeto aprovado no Programa Observatório da Educação.

Trata-se de um grupo heterogêneo que visa privilegiar os múltiplos olhares de profissionais de formações distintas e em diferentes momentos da carreira. A heterogeneidade é um aspecto que torna o grupo um espaço muito rico, dada a possibilidade de todos aprenderem na interação com os outros membros. Adotamos a sugestão de Ramos e Manrique (2015) de que o grupo seja caracterizado e analisado como uma Comunidade de Prática, conforme proposto por Wenger (2006), com professores voltados para a aprendizagem conjunta, ao compartilhar experiências e percepções, com a finalidade de aprender Matemática e aprimorar a prática docente.

\footnotetext{
${ }^{1} \mathrm{O}$ projeto de pesquisa foi submetido ao Comitê de Ética, cadastrado e aprovado na Plataforma Brasil - CAAE 54926216.2.0000.5482 - e os termos de consentimento livres e esclarecidos foram assinados em duas vias.
} 
Este artigo tem como foco investigar o processo formativo e a aprendizagem de dois professores que lecionam para o primeiro segmento do Ensino Fundamental. O objetivo é destacar elementos da aprendizagem para a docência que estão ocorrendo com a prática de planejar em conjunto a ação, propor a tarefa para a sala de aula e compartilhar a experiência na Comunidade de Prática.

Há a intenção de compreender não apenas as contribuições para a prática, mas também a observação e a reflexão que esses professores fazem sobre a atividade docente, quando influenciados pela Comunidade de Prática constituída neste núcleo da PUC-SP. Assim, importa definir a forma como essa influência e essa aprendizagem da docência ocorrem na relação que eles estabelecem com seus pares na Comunidade de Prática.

\section{Comunidade de Prática}

Wenger (2006, p. 4) propõe o conceito de comunidade de prática como uma teoria social de aprendizagem que "proporciona um marco conceitual do qual se pode deduzir um conjunto coerente de princípios e recomendações gerais para compreender e possibilitar a aprendizagem $^{2}$ ".

Ele considera que o processo de aprendizagem de um indivíduo ocorre pela prática social e que, portanto, o convívio com outros indivíduos é fundamental na constituição de si. De acordo com Wenger (2006), os seres humanos são essencialmente sociais e a aprendizagem ocorre no convívio com os pares. Além disso, o conhecimento é decorrente do envolvimento que o indivíduo tem com as situações de que participa. Assim, a aprendizagem é parte integral de nossas vidas cotidianas e os momentos de maior aprendizagem não estão necessariamente nas situações formais de aprendizagem. Aprendemos o tempo todo.

Ramos e Manrique (2015), apoiadas em Wenger, Mcdermott e Snyder (2002), consideram que Comunidades de Prática são formadas por grupos de pessoas que partilham interesses comuns e estão engajadas em adquirir e aprofundar conhecimentos e aprender juntos ao compartilharem práticas desse grupo que são sustentadas por um empreendimento conjunto.

O que Wenger propõe é uma maneira sistemática de falar sobre essas experiências familiares. Esse autor considera que "comunidades de prática podem ser concebidas como histórias compartilhadas de aprendizagem" ${ }^{3 "}$ (2006, p. 86, grifo do autor). Como resultado dessa abordagem, ele propõe seus estudos tendo como principal área de interesse a aprendizagem como participação social. E, para caracterizar a participação social como um processo de aprendizagem e conhecimento, propõe que uma teoria social de aprendizagem deve incluir quatro componentes: significado, prática, comunidade e identidade. O conceito de Comunidade de Prática integra esses quatro componentes que caracterizam a participação social como um processo de aprendizagem e de conhecimento. Eles apresentam-se profundamente interligados e devem ser considerados conjuntamente.

Significado é "uma forma de falar de nossa capacidade (mutante) - individualmente e coletivamente - para experimentar nossa vida e o mundo de forma significativa ${ }^{4}$ " (WENGER,

\footnotetext{
2 [...] it does yield a conceptual framework from which to derive a consistent set of general principles and recommendations for understanding and enabling learning.

${ }^{3}[\ldots]$ communities of practice can be thought of as shared histories of learning.(grifo do autor)

${ }^{4}[\ldots]$ a way of talking about our (changing) ability - individually and collectively - to experience our life and the world as meaningful.
} 
2006, p. 5). Trata-se daquilo que cada um sente, percebe e apreende da experimentação do mundo a sua volta.

Prática é a "forma de falar dos recursos históricos e sociais, dos marcos de referência e das perspectivas compartilhadas que podem sustentar o compromisso mútuo na ação ${ }^{5 "}$ (WENGER, 2006, p. 5). Ou seja, é a forma de participação e envolvimento na ação, levando em consideração a história e as perspectivas do indivíduo no empreendimento.

As comunidades são configurações sociais dos empreendimentos definidos como valiosos para o indivíduo e nos quais sua participação é reconhecida como competência. E identidade é o termo que ele utiliza para retratar as mudanças que a aprendizagem provoca no indivíduo, criando histórias pessoais de transformação no contexto de suas comunidades (WENGER, 2006).

Assim, é necessário associar a prática com a formação de comunidades e isto define um tipo especial de comunidade, uma Comunidade de Prática. Portanto, a expressão Comunidade de Prática deve ser tratada como uma unidade, pois seus termos constituintes se especificam mutuamente.

Wenger (2006, p. 48) considera que a "atividade chamada manual não é desprovida de pensamento e a atividade mental não é sem ação ${ }^{6}$ ". Então, para este autor, prática e teoria não só estão sempre juntas, mas, sobretudo, interagem entre si e interferem, constantemente, uma na outra. A teoria é fundamental para orientar a prática, que, segundo o autor, apresenta traços do conhecimento teórico que o indivíduo detém. Mais que isso, a prática é indispensável para que o indivíduo faça sucessivas aproximações da teoria.

Além disso, o autor propõe relacionar o conceito de prática à experiência para proporcionar significado. Segundo Wenger (2006, p. 51), "a prática é, em primeiro lugar, um processo pelo qual podemos experimentar o mundo e nosso engajamento com ele como significativo ${ }^{7 "}$. Nesta dinâmica de participação social, o autor cria a expressão negociação de significado para expor o processo pelo qual o indivíduo se integra e interage no grupo.

Wenger (2006, p. 52) explica que a negociação de significado ocorre pela "interação de dois processos constituintes", a participação e a reificação, que formam "uma dualidade que é fundamental para a experiência humana de significado"'. O significado é sempre um produto da negociação e há, na negociação de significado, uma dualidade fundamental pela participação e reificação. A participação é "a experiência social de viver no mundo em termos de afiliação em comunidades sociais e envolvimento ativo em empreendimentos sociais ${ }^{10}$ " (WENGER, 2006, p. 55).

Assim, a participação assume um significado mais amplo do que engajamento, não é o mesmo que colaboração e pode envolver relações harmônicas ou conflituosas, íntimas ou políticas, competitivas ou cooperativas. Conforme o uso proposto por Wenger (2006) para o termo, a participação é elemento integrante do indivíduo.

\footnotetext{
${ }^{5}[\ldots]$ a way of talking about the shared historical and social resources, frameworks, and perspectives that can sustain mutual engagement in action.

${ }^{6}[\ldots]$ so-called manual activity is not thoughtless, and mental activity is not disembodied.

${ }^{7}$ Practice is, first and foremost, a process by which we can experience the world and our engagement with it as meaningful.

${ }^{8}[\ldots]$ interaction of two constituent processes.

${ }^{9}[\ldots]$ a duality that is fundamental to the human experience of meaning.

${ }^{10}[\ldots]$ the social experience of living in the world in terms of membership in social communities and active involvement in social enterprises.
} 
Em relação à reificação, o autor também traz uma explanação bem detalhada para defender o sentido que quer atribuir ao termo. Inicialmente, pode-se dizer que reificação significa "tratar uma abstração como substancialmente existente ou como um objeto material concreto $^{11 "}$ " (WENGER, 2006, p. 58). Em língua inglesa, é utilizado, também, para transmitir a ideia de materialização de uma noção ou conceito. Ele explica que o termo reificação pode ser compreendido etimologicamente como fazer tornar-se coisa. É o "processo de dar forma a nossa existência produzindo objetos que congelam nossa existência em 'coisa'12" (WENGER, 2006, p. 58).

A ideia sutil que o autor quer capturar é de que "nós projetamos nosso significado no mundo e depois o perseguimos como se, de fato, existisse, como se tivesse uma realidade própria ${ }^{13}$ " (WENGER, 2006, p. 58). Pela reificação, nós criamos pontos de foco que permitem a negociação de significados de maneira organizada. $\mathrm{O}$ autor explica que a reificação pode ser relacionada tanto a um processo como a um produto. Ele utiliza o termo para se referir a "uma vasta gama de processos que incluem fazer, planejar, representar, nomear, codificar e descrever, assim como, perceber, interpretar, usar, reutilizar, decodificar e reformular ${ }^{14 ”}$ (2006, p. 59).

O autor explica que, em sua ação recíproca, participação e reificação são tanto distintos como complementares, não podem ser considerados separadamente e formam uma dualidade que é

[...] fundamental para a constituição de comunidades de prática, para sua evolução ao longo do tempo, para as relações entre as práticas, as identidades dos participantes e as amplas organizações nas quais as comunidades de prática existem ${ }^{15}$ (WENGER, 2006, p. 65).

A complementaridade entre participação e reificação reflete a dualidade inerente ao processo de negociação de significado, que tem esses dois elementos como constituintes intrínsecos. Na participação as pessoas se reconhecem umas nas outras. Na reificação elas se projetam no mundo. Assim, há um contraste entre mutualidade e projeção. Nas palavras de Cyrino (2011, p. 381), "a dualidade da participação e da reificação tem um papel fundamental na experiência de negociar significados na prática". Participação e reificação são conceitos que se complementam e não podem ser considerados separadamente.

Wenger (2006) considera que a aprendizagem que ocorre em uma Comunidade de Prática é dotada de muito significado. Considerando que a prática é uma história compartilhada de aprendizagem, ela requer a aproximação entre os participantes. Ele explica que o fato de que os membros interagem, fazem coisas juntos, negociam novos significados e aprendem uns com os outros já é inerente à prática. Mais que isso, é assim que a prática evolui. O ingresso de novos participantes é parte da dinâmica e da existência de uma comunidade de prática. Os experientes compartilham sua competência com novas gerações reproduzindo o mesmo processo pelo qual eles se desenvolvem.

\footnotetext{
${ }^{11}$ To treat (an abstraction) as substantially existing, or as a concrete material object.

12 [...] the process of giving form to our experience by producing objects that congeal this experience into thingness".

${ }^{13}$ We Project our meanings into the world and then we perceive them as existing in the world, as having a reality of their own.

14 [...] a wide range of processes that include making, designing, representing, naming, encoding, and describing, as well as perceiving, interpreting, using, reusing, decoding, and recasting.

$15[\ldots]$ is a fundamental aspect of the constitution of communities of practice, of their evolution over time, of the relations among practices, of the identities of participants, and of the broader organizations in which communities of practice exist.
} 
Uma Comunidade de Prática pode se constituir a partir de grupos com propostas colaborativas e é excelente alternativa para a formação continuada de professores, pois a interação entre os pares contribui para o desenvolvimento mútuo de saberes e práticas pedagógicas (LAVE e WENGER, 1991). A participação em uma Comunidade de Prática permite ao professor expor suas dúvidas, medos e perspectivas sem se preocupar com a aprovação ou críticas de seus pares. (SARAIVA e PONTE, 2003)

\section{O método utilizado para coleta de dados}

Retomando a memória e os registros do início do percurso do grupo, lembramos que as primeiras ações propostas tinham o intuito de criar, entre os participantes, um sentimento de confiança, integração e parceria. Entendia-se que, naquele primeiro momento, era necessário criar a identidade do grupo e consolidar, entre os integrantes, as perspectivas e expectativas em relação ao trabalho que se pretendia desenvolver ao longo dos quatro anos de duração do projeto vinculado ao Programa Observatório da Educação. Isso porque entendemos que a aprendizagem da docência é um fenômeno social e a aprendizagem dos professores é um processo de socialização profissional (CANÁRIO, 1997; GARCÍA, 1998).

Ao longo desses anos, os participantes vêm entrando em contato com teorias que subsidiam o trabalho, escolhem temas de estudo, sugerem e elaboram tarefas, compartilham momentos de discussão, produzem narrativas e refletem sobre a prática. Estes são alguns dos elementos considerados como constituintes de um passo inicial para a mudança que gera o aprendizado da prática docente.

Assim, em uma primeira reunião, foi proposto aos participantes, um subgrupo da Comunidade de Prática, que planejassem uma atividade para ser desenvolvida em sala de aula e, posteriormente, ser analisada na Comunidade de Prática. Este artigo aborda a descrição e a análise de duas duplas, cada uma composta por um membro sem experiência docente e um membro experiente atuando nos anos iniciais do Ensino Fundamental, conforme Quadro 1.

Quadro 1 - Perfil dos participantes

\begin{tabular}{|l|l|l|l|}
\hline Participante & $\begin{array}{l}\text { Formação quando } \\
\text { começou a participar da } \\
\text { comunidade de prática }\end{array}$ & $\begin{array}{l}\text { Formação quando } \\
\text { participou da ação }\end{array}$ & Experiência docente \\
\hline Isabela & $\begin{array}{l}\text { Era estudante do quarto } \\
\text { ano de Pedagogia em } \\
\text { uma universidade de São } \\
\text { Paulo. }\end{array}$ & $\begin{array}{l}\text { Estava recém formada } \\
\text { em Pedagogia e não } \\
\text { estava lecionando. }\end{array}$ & $\begin{array}{l}\text { Professora auxiliar em } \\
\text { uma creche atuando com } \\
\text { bebês até dois anos de } \\
\text { idade. }\end{array}$ \\
\hline Carlos & $\begin{array}{l}\text { Estava formado em } \\
\text { Pedagogia } \\
\text { aproximadamente nove } \\
\text { anos. }\end{array}$ & $\begin{array}{l}\text { Lecionava para um } \\
\text { quarto ano em uma } \\
\text { escola municipal de São } \\
\text { Paulo. }\end{array}$ & $\begin{array}{l}\text { Leciona em uma sala de } \\
\text { quarto ano em uma } \\
\text { escola municipal de São } \\
\text { Paulo. Está na rede } \\
\text { municipal há seis anos. }\end{array}$ \\
\hline Júlia & $\begin{array}{l}\text { Era estudante de terceiro } \\
\text { semestre de Pedagogia } \\
\text { em uma faculdade de São } \\
\text { Paulo. }\end{array}$ & $\begin{array}{l}\text { Cursava o sétimo } \\
\text { semestre, penúltimo } \\
\text { semestre do curso de } \\
\text { Pedagogia. }\end{array}$ & $\begin{array}{l}\text { Auxiliar de sala em um } \\
\text { quinto ano em uma } \\
\text { escola particular de São } \\
\text { Paulo }\end{array}$ \\
\hline
\end{tabular}




\begin{tabular}{|l|l|l|l|}
\hline Camila & $\begin{array}{l}\text { Cursou o Magistério e } \\
\text { posteriormente formou- } \\
\text { se em Pedagogia. }\end{array}$ & $\begin{array}{l}\text { Estava lecionando em um } \\
\text { quinto ano pela manhã e, } \\
\text { à tarde, em um segundo } \\
\text { Lecionava para o } \\
\text { primeiro ano do Ensino } \\
\text { Fundamental 1. }\end{array}$ & $\begin{array}{l}\text { Leciona há mais de vinte } \\
\text { anos. uma escola } \\
\text { concursada na Prefeitura } \\
\text { munal de São Paulo. }\end{array}$ \\
\hline
\end{tabular}

Nessa reunião, eles planejaram uma tarefa de Matemática para ser proposta em sala de aula. O desenvolvimento de cada atividade em sala de aula foi filmado e analisado pela dupla. Posteriormente, alguns trechos foram selecionados para serem exibidos aos demais participantes da Comunidade de Prática.

O roteiro de coleta de dados foi organizado com inspiração no processo de autoconfrontação e autoconfrontação cruzada proposto por Yves Clot (2007) para analisar a atividade do sujeito. Para este autor, a tarefa de rever suas ações em imagens previamente selecionadas e contar para si mesmo e para o outro o que ocorreu faz surgirem novas compreensões acerca das ações desenvolvidas.

Clot (2007) propõe uma tríade para analisar a ação do sujeito. Esta tríade é composta pelo objeto, pelos conflitos dos outros e pelos próprios conflitos. O ponto de equilíbrio da ação é conquistado na conjunção dos elementos que a compõem. Esses elementos servem, ao mesmo tempo, de equilíbrio da ação e de ponto de conflito.

Assim, o autor explica que, em um grupo de trabalhadores em determinada atividade, a ação de cooperação que serve temporariamente de ponto de equilíbrio foi gerada no trabalho realizado por eles sobre os conflitos no objeto, sobre os conflitos dos outros e sobre seus próprios conflitos. (CLOT, 2007)

Clot (2007, p. 124) considera que é por intermédio do exame da atividade dirigida do ponto de vista do seu desenvolvimento que se torna possível "compreender as relações entre os inesperados e os esperados de uma situação". O autor propõe que se crie uma situação que permita essa ampliação das distâncias contextuais. Recriar uma situação artificial em que estejam presentes o sujeito e o pesquisador, envolvidos em uma dinâmica que Clot (2007) chama de autoconfrontação. Nestas circunstâncias, há a descrição pelo sujeito, o olhar do pesquisador e a compreensão da situação pela observação do sujeito, com nova interpretação pelo pesquisador.

Clot entende que esta forma de tratar os dados não é "nem explicação externa dada pelo pesquisador, nem simples descrição do vivido pelo sujeito, a análise associa explicação e compreensão quando a mesma atividade é re-descrita num novo contexto" (2007, p. 130). Segundo ele, ocorre uma boa descrição na redescrição e, quando este novo contexto inclui os colegas de trabalho, ou seja, um terceiro olhar, recebe o nome de autoconfrontação cruzada. $\mathrm{O}$ autor afirma que, "realizada em colaboração entre o pesquisador e os trabalhadores envolvidos, ela fornece muitas vezes a explicação esperada." (CLOT, 2007, p.130-131)

Desta forma, a autoconfrontação cruzada permite que se realize a análise do trabalho e que difere da autoconfrontação clássica apenas pelo fato da primeira acrescentar os pares no processo de observação. A verbalização provoca, então, a reflexão e a reconsideração acerca do trabalho desenvolvido, dando a ele um novo sentido, promovendo nova compreensão e provocando novo comportamento. Na nossa interpretação, proporciona desenvolvimento e aprendizagem. 
É importante salientar que, nesse tipo de pesquisa e análise de dados, é necessário dispor de tempo para que se possam obter os resultados. É o tempo vivido que vai permitir que se processe o resultado que se busca. Mais que isso, o próprio tempo é, ele mesmo, um instrumento de pesquisa.

Sendo assim, não se trata apenas de coletar os dados e registrar as evidências. Mais que isso, deve ocorrer uma participação plena dos sujeitos envolvidos na ação, para que suceda a produção de dados nas várias etapas propostas. Essa participação precisa de tempo para se estabelecer e produzir as condições que serão observadas, vivenciadas e reconcebidas pelos participantes.

No trabalho descrito neste artigo foram planejadas quatro fases, que consistiram de planejamento da atividade, desenvolvimento da atividade em sala de aula, reflexão provocada pela apresentação de cenas da filmagem da atividade, que envolveu a pesquisadora, um membro sem experiência docente e o professor experiente de cada dupla e uma fase com a participação da Comunidade de Prática, em que foram apresentados trechos das filmagens. Foram considerados, portanto, os pontos de vista da pesquisadora, de estudantes de Pedagogia, de professores de sala de aula e da Comunidade de Prática.

Na primeira fase, os participantes escolheram e planejaram uma atividade de aula de Matemática para ser proposta nas salas de aula dos professores experientes envolvidos. A proposta inicial era que os membros sem experiência docente do curso de Pedagogia fizessem uma intervenção em sala de aula, em parceria e sob o olhar do professor regente da turma. $\mathrm{O}$ roteiro e o planejamento inicial da ação ocorreram em conjunto, com a participação dos membros com e sem experiência docente, envolvidos nesta pesquisa. No entanto, conforme as ações foram sendo desenvolvidas em sala de aula, as estudantes assumiram o papel de auxiliares de sala e as intervenções foram propostas pelos professores regentes.

Depois das situações de sala de aula, houve uma reunião com cada dupla e a pesquisadora, para assistirem à gravação da aula, fazer comentários e reflexões acerca do ocorrido e escolherem alguns trechos para serem exibidos na reunião geral com a comunidade de prática. Na quarta fase, os participantes da Comunidade de Prática assistiram, em conjunto com os participantes das ações, à edição das atividades gravadas nas aulas. A edição, de aproximadamente 25 minutos de vídeo, foi exibida integralmente antes das intervenções e comentários. Em seguida, ocorreu uma ampla discussão provocada pelas cenas exibidas, promovendo uma reflexão acerca da docência.

\section{Análise dos Dados}

Na reunião de planejamento da atividade, estavam presentes os membros com e sem experiência docente envolvidos na ação. Inicialmente, foi explicado o propósito daquela reunião, com um resumo do que era esperado nas quatro fases e qual era o objetivo da pesquisa. Além disso, foi feito um breve resumo do percurso do grupo para que eles pudessem se lembrar das tarefas de planejamento e propostas de ações sala de aula que já haviam sido desenvolvidas algumas vezes na Comunidade de Prática. A ideia era refazer, de certa forma, o mesmo percurso que já havia sido feito no grupo em ocasiões passadas.

Logo, os participantes foram organizando as duplas e começaram a pensar em uma atividade que gostariam de desenvolver nas suas salas de aula e que fossem interessantes para as estudantes de Pedagogia. Esse tipo de tarefa já havia ocorrido outras vezes na Comunidade 
de Prática. Desde os primeiros encontros do grupo já havia surgido o interesse em vivenciar e estudar práticas de sala de aula e temas matemáticos na perspectiva da resolução de problemas. Foram desenvolvidas várias ações nesse sentido (TINTI et al, 2016).

Depois de um longo processo de negociação, as duplas consideradas neste artigo escolheram trabalhar com o jogo Cara a Cara Numérico nas salas de quarto ano, do professor Carlos, e de quinto ano, da professora Camila.

Nesse jogo, uma criança segura uma ficha com um número, sem ver qual é e faz perguntas ao grupo. As outras crianças do grupo, que vêem o número impresso na ficha, só podem responder sim ou não. Depois de algumas perguntas, espera-se que a criança que faz as perguntas tire algumas conclusões e descubra que número está gravado na ficha que ela tem em mãos.

Professora Elisa: ... E o cara a cara numérico era muito legal. Vários números diferentes, vários números. Eram grupos, trios, eu fazia de trio, acho, não lembro. E aí, pegava um número e punha na testa. Aí, sou par? Sim. E aí é legal, no quarto ano, porque eles precisam lançar mão de todo o conhecimento matemático que eles têm. Professora Camila: O número que está na testa dele, ele não está vendo? Professora Elisa: É. Eu tenho até dezena de milhar? Por exemplo. Pesquisadora Mariana: Sou menor que dez, sou maior que dez? Professora Elisa: É, e eu tinha um número.

Professora Camila: Olha, se fosse esse daí, no meu quinto ano ia ser muito legal. Essa atividade no quinto ano! Porque aí eles já têm um repertório muito grande. Eles fazem uma pergunta e... [A professora Camila faz gestos de estalar os dedos, querendo comunicar que as crianças responderiam rapidamente.] No quinto ano, esse jogo, nossa! Porque eles já têm noção do que é par, ímpar.

Surge uma discussão em relação ao preparo do material. São consideradas as diferenças de características de cada professor. Alguns preparam um material mais elaborado, outros são mais práticos, elaboram o material mais rapidamente, para ser utilizado uma ou duas vezes e ser descartado. A professora Camila volta a imaginar o desempenho da turma com o jogo e se empolga com a ideia.

Professora Camila: Faríamos o quê? Alguns números? Sete números, vai... Nossa! Esse jogo aí, ia dar muito bem. Acho que eles fariam perguntas boas.

Professora Elisa: Para o quarto ano, dá para fazer. [A pesquisadora Mariana sugere que se jogue para verificar como seria a utilização do jogo na sala de aula.]

Professora Camila: Isso! Podemos jogar aqui.

Ainda na reunião de planejamento, o professor Carlos se interessa em saber como é o jogo e alguns participantes iniciaram uma simulação.

Professor Carlos: Eles que fazem as perguntas e eles mesmos respondem, né? Na testa e ele que faz as perguntas.

Professora Elisa: Eu vou fazer, eu vou fazer aqui... Me dá um número... eu sou par? Eu tenho até centena?

Diante das expressões de negação de alguns a professora Elisa continua.

Professora Elisa: Então, é só dezena.

Professora Camila: sim. 
Professora Elisa: Eu sou maior que vinte?

Professora Camila: não.

No diálogo que segue, é possível perceber como surgiu, na reunião de planejamento, a ideia da professora Camila de elaborar o cartaz com as sugestões de perguntas, que ela afixou no quadro, em sua sala de aula, durante o jogo.

Professora Camila: Para o quinto ano vai dar super certo. Agora, para o segundo eu já não sei, porque eles não vão ter o que perguntar.

Professor Carlos: Para os meus dá, porque primeiro eles não vão saber o que perguntar, mas aí eles vão começar a copiar as perguntas.

O professor Carlos, em sua sala de aula, preferiu expor o jogo fazendo uma simulação. Além disso, ele propôs escrever as perguntas no quadro, que é o desdobramento da ideia de uns copiarem as perguntas dos outros.

Entre a primeira reunião e a proposta da tarefa em sala de aula, não se observou movimento de planejamento entre as duplas. Posteriormente, descobriu-se que a professora Camila e o professor Carlos planejaram a atividade individualmente, ao longo do processo de docência, no movimento cotidiano de organização das aulas, sem o envolvimento de Júlia e Isabela.

No dia da aula na sala da professora Camila, quando a pesquisadora e a Júlia chegaram, encontraram as crianças esperando pelas visitantes e já sabiam que haveria uma atividade diferente do usual. Havia um cartaz afixado no quadro com algumas sugestões de perguntas para o jogo.

Durante o jogo, na sala da professora Camila, pode-se perceber que o cartaz foi tomado como um roteiro pelas crianças. Por mais que a professora Camila reforçasse a ideia de que o cartaz tinha apenas algumas sugestões de perguntas, as crianças recorriam a ele com muita frequência para elaborar suas questões ao colega.

Na sala do professor Carlos, foi feita a opção de explicar o jogo conforme se fazia uma partida simulada com Isabela e envolvendo as crianças. Em seguida, ele escreveu no quadro, conforme foi recapitulando com as crianças, as perguntas que havia feito na simulação e combinou com elas que acrescentaria novas perguntas no quadro, conforme fossem surgindo. Foi um ótimo estímulo para as crianças pensarem em novas perguntas.

Posteriormente, surgiu, também nesse caso, o comentário em relação às perguntas que as crianças deveriam fazer durante o jogo. Isabela percebeu que algumas crianças ficaram presas às ideias que já estavam no quadro. $\mathrm{O}$ professor Carlos ficou satisfeito com o desempenho delas. A pesquisadora comentou que, da forma como foi proposto o jogo na sala do professor Carlos, houve o estímulo para que as crianças criassem novas perguntas.

Isabela: As crianças ficaram bastante presas nas que estavam na lousa.

Professor Carlos: Mas, eu achei que eles perguntaram muito. A lousa ficou quase cheia!

Pesquisadora Mariana: Dessa forma, eles foram estimulados a criar novas perguntas.

Com as filmagens das aulas, foram geradas imagens que foram selecionadas para serem exibidas para as duplas. O objetivo era fazer a autoconfrontação, com inspiração no que é proposto por Clot (2007). Rever a própria atuação tendo alguém junto e, depois, fazer a mesma 
coisa na Comunidade de Prática, tendo o grupo todo como expectador, permite mais de um ângulo de visão de si mesmo. Pois, em cada uma dessas situações a pessoa assume um papel diferente.

A pesquisadora preparou uma seleção prévia para que cada estudante observasse algumas cenas das fases 1 e 2, começando com alguns trechos da filmagem da reunião de planejamento da atividade e, em seguida, alguns trechos da aula. Inicialmente, houve a explicação bem detalhada do propósito da reunião. A pergunta que deveria ficar na mente durante esta fase era: o que eu aprendi com essa aula? A intenção era saber de que forma a participação na Comunidade de Prática e na reunião de planejamento, que já é decorrente dessa participação, interferem na ação de propor uma tarefa de Matemática em sala de aula.

Houve, então, a exibição das cenas com o objetivo de lembrar um pouco das duas situações e ver o eles achavam das coisas que foram aprendidas. Para cada dupla, as cenas da reunião de planejamento eram semelhantes e havia as cenas correspondentes à aula da dupla.

Durante a observação das filmagens pelas duplas, a professora Camila e a Júlia estavam um pouco tensas com a situação e bem ansiosas de se verem nas filmagens. Demorou um pouco para ficarem mais à vontade. $\mathrm{O}$ professor Carlos estava muito interessado em observar as cenas e saber o que deu certo e como foi o desempenho. Isabela é muito tímida, mas parecia tranquila em relação a essa situação.

A pesquisadora foi fazendo perguntas para provocar e conduzir o processo. As cenas foram sendo interrompidas com comentários e perguntas acerca dos sentimentos e percepções deles em relação ao ocorrido, tanto pela observação como pela memória dos fatos. O professor Carlos comentou que a atividade que propuseram para as crianças, embora pareça simples, apresenta desafios para o professor.

Essa atividade, ela parece simples, mas ela é complexa, porque o professor, na frente ali, é preciso ir sistematizando as respostas que eles vão dando. Porque, de acordo com a reação do grupo, é que você vai direcionando a atividade. Não é algo previsível. A gente acha que vai acontecer de um jeito, mas, quando está acontecendo é que você vai sistematizando. Eles estão perguntando isso, eles estão fazendo assim, isto está dando certo. (Professor Carlos)

O professor Carlos comenta que percebeu que em alguns grupos poucos alunos estavam acertando a brincadeira e considerou que isto poderia refletir negativamente se a conclusão fosse pelo resultado do jogo.

E até hoje eles não sabem quem ganhou porque teve acho que dois ou três grupos que só um aluno acertou em cada grupo. (Professor Carlos) 
Durante a reunião com a professora Camila e com a estudante Júlia surgiu a curiosidade de saber de onde surgiu a ideia de fazer um cartaz com as perguntas.

Pesquisadora Mariana: Foi a Camila que fez o cartaz? E como que você fez? Fez sozinha? Ou negociou com o grupo?

Professora Camila: não, nesse momento, fiz sozinha. Fiz sozinha porque eu pensei assim: como eles nunca haviam jogado, que perguntas eles poderiam fazer? Então, eu pensei: vou dar umas dicas de perguntas.

Na sala da professora Camila, a sistematização foi feita depois do intervalo. As crianças voltaram para a formação habitual, em fileiras, e a professora Camila foi conduzindo o processo, juntamente com a pesquisadora, para que as crianças analisassem as perguntas do cartaz e pensassem em modificações necessárias para a próxima vez que fossem jogar. Poderiam pensar em outras para acrescentar ou modificar aquelas. As participações das crianças foram surpreendentes.

No final, eles fizeram perguntas que nem a gente imaginava. As crianças têm umas perguntas ótimas. Porque eles jogaram, eles perceberam. Alguns vão além. Têm a ideia. E aí eles puseram, olha! O cartaz tem assim: tem par? Tem ímpar? Eram as primeiras perguntas. Oh, se a gente já perguntou se é par, não precisa perguntar se é impar. (Júlia)

Nesse diálogo aparece a percepção da professora Camila de que a situação permite aprendizagem, conclusões importantes para aprimorar a prática docente.

Eu gostaria muito de ver o final. Eu estou curiosa para ver o final. Aquela parte que eles começam a falar: podia ter feito assim, podia ter feito assado. Como que foi? A parte da sistematização, depois do recreio, depois que eles voltaram para o lugar. (Professora Camila)

A pesquisadora pergunta o que ela aprendeu com a experiência. Ela responde:

Sabe o que eu tiro nesse pedacinho? Replanejar o meu próximo bimestre. Porque aí eu consegui parar um pouco e observar mais... Então, serviu como replanejar. Permite uma avaliação do aluno, avaliar e replanejar. (Professora Camila)

O passo seguinte era promover a observação da filmagem pela Comunidade de Prática e havia a intenção de passar todo o filme e depois abrir para os comentários do grupo. Em continuidade a este procedimento, estava previsto que houvesse a discussão do que ocorreu e foi exposto no recorte da filmagem, podendo incluir relatos de memória, com a participação do grupo todo. Bastou uma pergunta da pesquisadora e a discussão teve início, já com a participação plena e descontraída de todos.

Algumas falas demonstram que a reflexão possibilitada pela filmagem é produtiva para a aprendizagem da docência. Por exemplo, no diálogo abaixo aparece a possibilidade que o jogo oferece para que o professor acompanhe de perto o desempenho das crianças, suas dúvidas, hipóteses que precisam ser ajustadas.

Houve, no momento do jogo, momentos em que nós percebemos a dificuldade deles. Uma criança falou assim: Era 54, acho. Não me lembro. É par ou é impar? Elas 
perguntaram. Ela falou: é par e é impar. Aí, eu falei: Ela não sabe o que é! Então, olha só, lá no meio, nas atividades, ela se sai bem. Mas ela não sabia exatamente o que é. Tanto é que eu retomei, quando vocês foram embora. (Professora Camila)

Na sala do professor Carlos também houve a percepção do conhecimento matemático das crianças, essa questão delas não terem essa noção. A criança pergunta se é maior que cinquenta ou menor que cinquenta e depois faz outra pergunta que demonstra que não relacionou a resposta com a pergunta seguinte.

O professor Carlos faz um depoimento em que aparece essa questão da avaliação formativa. Ele demonstra a ação de observar o desempenho das crianças, que norteia parte do trabalho docente, o medo das crianças não se desempenharem bem e ele ficar decepcionado com o resultado de seu trabalho, a preocupação com a forma como a tarefa apresenta os conteúdos, exigindo a mobilização de conhecimentos variados pelas crianças.

\begin{abstract}
Mas eu fiquei com medo deles não saberem, eu não falei nos nossos encontros, mas eu fiquei com medo disso. Porque eu sei o que eu trabalhei, a gente sabe o que eles sabem. Então, a gente sabe o que eles sabem. Mas, em nenhum momento eu dou desse jeito. Tudo, todas aquelas perguntas... Em nenhum momento a gente trabalha assim. (Professor Carlos)
\end{abstract}

O professor Carlos fez comentários de que ficou muito orgulhoso com o fato de que as crianças tiveram um bom desempenho no jogo. Demonstraram que aprenderam o que foi ensinado durante as aulas. Ele finaliza sua fala assim:

E aí eu fiquei muito feliz, porque eles sabem. O meu medo era da sala inteira não saber. De repente eu falar: qual que é a centena? E nenhum, ninguém falar nada. E, não. A maioria da sala respondeu. Então, aí você fica contente. Eu fiquei contente. Nossa, eles são demais, esses meus alunos! (Professor Carlos)

\title{
CONSIDERAÇÕES FINAIS
}

Esse processo, que foi elaborado inicialmente para observar o aprendizado de participantes sem experiência docente do curso de Pedagogia, colocou em evidência, de maneira muito forte, a percepção de aprendizado da docência pelos professores dos anos iniciais do Ensino Fundamental, o que motivou a escrita deste artigo. Os participantes da Comunidade de Prática estão interessados e, de certo modo, comprometidos em aprender juntos na empreitada de melhorarem ou de adquirirem novos conhecimentos que possam ser colocados em prática em sua atuação profissional em sala de aula.

Foi possível observar, nessa ação, elementos que contribuem para a aprendizagem docente pela reflexão sobre a prática, como alguém aprende a ser professor e que elementos desse aprendizado decorrem da participação na Comunidade de Prática. Nos diálogos surgidos nas situações observadas é intensa a percepção de cada um dos participantes em relação à atuação e ao comportamento em sala de aula e o que é que eles acham que aprenderam com a situação. É evidente o aprendizado dos participantes na interação com seu par e entre os integrantes da Comunidade de Prática.

No encontro geral do grupo estava previsto que houvesse a discussão do que ocorreu e foi exposto no recorte da filmagem, podendo incluir relatos de memória, com a participação do 
grupo todo. Havia a expectativa de que surgisse uma discussão rica, incluindo a constatação de situações que foram previstas e que não foram previstas, como foram solucionadas e o motivo de terem sido tratadas daquela forma, o que foi possível prever e planejar na fase inicial e o que ficou esquecido ou, até mesmo, o que não foi previsto. Este envolvimento do grupo na discussão já havia ocorrido em outras ocasiões e era esperado que se repetisse desta vez.

No entanto, observou-se que as evidências de aprendizagem da docência apareceram com maior ênfase na reunião da dupla com a pesquisadora. Ocorreu, no encontro das duplas, a discussão acerca das ações em estudo, incluindo as reflexões acerca do próprio aprendizado, do aprendizado do outro e as trocas de experiências e percepções em relação à tarefa desenvolvida. Houve, inclusive, muitos momentos de constatação das diferentes possibilidades de aprendizagem pelas crianças.

Na reunião geral da comunidade de prática, ocorreu, conforme a expectativa, um grande envolvimento dos participantes, mas os depoimentos evidenciam principalmente a reflexão em relação a sua própria atuação docente. Ou seja, o movimento de observar a atuação do outro provocou reflexões acerca de suas próprias ações.

Isto permite concluir que esse processo se configura fortemente como uma prática que promove aprendizagem da docência. Rever e refletir acerca de sua própria atuação, compartilhar essas percepções com seus pares, ver e ouvir o movimento do outro nesse mesmo processo se apresenta como oportunidade de se conscientizar das próprias ações em sala de aula, rever procedimentos e concepções. Isto ajuda a promover a mudança de comportamento necessária para aprimorar a própria prática.

O professor, individualmente ou com outras pessoas, revê, renova e amplia os seus compromissos quanto aos propósitos do ensino e adquire e desenvolve, de forma crítica, o conhecimento, as técnicas e a inteligência, tanto cognitiva como afetiva, essenciais a uma prática profissional de qualidade com os alunos, no contexto escolar. Essas trocas enriquecem as discussões e as percepções que cada um tem da sua prática pedagógica, promovendo assim reflexões sobre sua formação docente.

\section{REFERÊNCIAS}

CANÁRIO, R. A escola: o lugar onde os professores aprendem. Universidade de Aveiro. I Congresso Nacional de Supervisão na Formação. Mimeo, 18-20 de dezembro, 1997.

CLOT, Yves. A função psicológica do trabalho. $2^{\mathrm{a}}$ ed. Petrópolis, RJ: Vozes, 2007.

CYRINO, M. C.C. T.; CALDEIRA, J. S. Processos de negociação de significados sobre pensamento algébrico em uma Comunidade de Prática de formação inicial de professores de matemática. Revista Investigações em Ensino de Ciências. Porto Alegre, RS, v. 16 (3), pp. 373401, 2011.

GAMA, R.; PASSOS, L.; CARDOSO, V. Rede Colaborativa de Práticas na Formação de Professores que ensinam Matemática: múltiplos olhares, diálogos e contextos. Edital $n^{o}$ 049/2012/CAPES/INEP, Projeto do Observatório da Educação, 2012.

GARCÍA, C. M. Pesquisa sobre formação de professores: conhecimento sobre aprender a ensinar. Revista Brasileira de Educação, v. 9, p. 51-75, set, out, nov, dez, 1998. 
LAVE, Jean; WENGER, Etienne. Situated Learning: Legitimate Peripheral Participation. Cambridge University Press, 1991.

RAMOS, W. R.; MANRIQUE, A. L. Comunidade de Prática de professores que Ensinam Matemática como Espaço de Negociações de Significados sobre a Resolução de Problemas. Bolema, Rio Claro (SP), v. 29, n. 53, p. 979-997, dez. 2015.

SARAIVA, M.; PONTE, J. P. O trabalho colaborativo e o desenvolvimento profissional do professor de Matemática. Quadrante, 12, p. 25-52, 2003.

TINTI, D. et al. OBEDUC: análise de aprendizagens docentes num contexto formativo sobre resolução de problemas. Zetetiké, FE/UNICAMP \& FEUPP, v. 24. N. 45, jan/abr, 2016.

WENGER, E.; MCDERMOTT, R.; SNYDER, W. M. Cultivating Communities of Practice: a guide to managing knowlwdge. Boston: Harvard University Press, 2002.

WENGER, Etienne. Communities of Practice: Learning, Meaning and Identity. New York, USA: Cambridge University Press, 1998, 14 ${ }^{\text {th }}$ printing, 2006.

Recebido em 12/09/2016

Aprovado em 11/12/2016 